Up to this point, the new explanation of the origin of drift gold seems feasible, and, indeed, almost conclusive. The gold is present in minute quantities in the water of the drift, and this fact has been conclusively demonstrated experimentally by various investigators, among whom may be mentioned Messrs. Newberry and Skey. But it is one thing to prove that chloride of gold exists in the drift waters, and quite another thing to suggest in what manner and by what agency the precious metal has been reduced from its salt, and deposited in the form of coarse or fine grains or in that of large and strangely-shaped nuggets. Precipitation was the first and most obvious suggestion. The addition, for instance, of a minute quantity of sulphate of iron to a solution of chloride of gold would cause the formation of minute particles of metallic gold, and sulphate of iron, of course, is present in Nature abundantly. But such an explanation would only account for the formation of the very finest gold dust. It would give no solution of the origin of coarse gold and nuggets, nor would it account for any of the many peculia anomalies of which I shall presently mention some striking examples.

In order to afford a possible extension of this purely chemical theory which might give a clue to the origin of nuggetty gold, it has been pointed out that if a crystal of some sulphide, such as iron pyrites, he immersed in a solution of chloride of gold, it will be covered with a film of metallic gold. Following the track of investigation thus apparently opened up, it has been ingeniously suggested that possibly the material of the metallic sulphide, and that of the golden film, may be regarded as a sort of miniature electric battery, in which the gold would form one anode and the pyrites the other. A current would pass between the two, and the result would be the deposition of metallic gold upon the film, at the same time that the material of the pyrites would continually become decomposed. The electroplater, in his laboratory, places the salt of gold in his bath, and uses an ordinary battery from which to obtain a current sufficiently strong to deposit gold upon the articles to be plated. But in this case it was suggested that the article to be plated, which was the film of gold itself, might be regarded as one of the elements supplying the current. The theory seems from the outset somewhat far-fetched, and it is open to very strong objections on the ground of improbability. The amount of material which the electroplater has to use up in order to deposit an ounce of gold is very considerable, even in the most efficient forms of batteries known to science. It is scarcely conceivable that a piece of pyrites, weighing about two pennyweights, would, by its decomposition, afford sufficient current to deposit an ounce of gold. Yet something of the sort would have to be established before it could be proved that electro-chemical action in situ supplies the electric current as a reducing agent.

In seeking for an explanation of the deposition of gold which would afford a surer or more probable basis for conjecture, I was at first mainly influenced by two remarkable facts which could hardly be referred to any imaginable phenomena of a chemical or electro-chemical origin. These were that in a drift supplying gold in abundance it is by no means uncommon to find a patch in which the gold gives out altogether, and is picked up further along the line; and the second was that there has always been observed at many of the leading goldfields a certain correspondence between the richness of the alluvial drifts and reefs and the points of the compass. The direction in which the richest drifts run may vary from one locality to another. But no matter how broken in contour the country may be, there is almost always a marked parallelism between the richest drifts.

Taking these and one or two other facts as a starting-point, I was led to form the hypothesis that the probable origin of the deposition of gold is to be found in thermo-electric earth-currents, probably generated by the unequal heating of the surface of the earth by the sun's rays in passing from east to west. This theory of earth-currents has attracted a good deal of attention in Australia, and it is remarkable how rapidly facts in support of it have been brought forward during the past few months. It would be impossible for me, within brief limits, to refer to all of these; but it will be of interest to summarize a few of the leading points :-

(I) The existence of earth-currents has been frequently demonstrated, and has attracted special attention since the invention of the telephone. In 1880, Prof. Trowbridge, of Harvard, conducted a series of experiments at the Observatory, and recorded it as one of his results that these currents appeared to be most pronounced along the water-courses.
(2) In Victoria remarkable instances of deflection of the com. pass have been particularly numerous, hinting at the presence of strong currents, more especially at the lines of junction between permeable and impermeable rocks.

(3) There is a remarkable relation between the conductivity of the adjacent rock country and the richness of an alluvial drift. Thus, in passing through slate or below an overhanging mass of basalt, the drift is generally richer than in passing through moist sandstone, suggesting that, where an earth-current is concentrated along the line of the water in consequence of the presence of rocks of low conductivity, the process of deposition has been facilitated.

(4) There are places at which the gold gives out altogether, although no discernible change has taken place in the nature of the country. These places seem to be the localities of a sort of short-circuiting, which we may readily suppose to take place very frequently in earth-currents.

(5) At particular pinched localities the current would be peculiarly strong, and would lead to the formation of nodules or nuggets of gold, the existence of which cannot be satisfactorily explained by any chemical theory hitherto advanced.

(6) Nuggets of an alloy of gold and copper have sometimes been met with, and the two metals have even been found to lie in alternate layers, suggesting that at one time a copper salt, and at another a gold salt, has been subjected to the action of a reducing current.

(7) In presence of a large amount of organic matter, it is almost invariably found that a drift becomes especially rich. The formation of acid by decomposition is what would be peculiarly required to facilitate the passage of an earth-current through the water of an underground drift, the existence of free acid being the requirement for an artificial electro-depositing bath.

(8) Conversely, the vicinity of large masses of calcite has been observed to be most inimical to the richness of a drift, and, of course, this could be explained by the fact that the carbonate of lime would destroy the free acid, and reduce the conductivity of the water so as to impede the transmission of a current.

(9) The peculiar shapes of the grains of what is known as coarse gold, are very suggestive of the action of a feeble current in piling up the metal upon the prominent portions, and leaving deep indentations between. Electric action of an extraneous nature is also strongly indicated by the strange strings and filaments which are constantly being met with.

(ro) If we accept the crenitic theory of the origin of quartz reefs, the theory of earth-currents would at once apply with particular force to show how the action of such currents in hot siliceous solutions would produce a formation of gold simultaneous with that of quartz, thus accounting for the finely divided state of the gold in such reefs.

(II) At the same time it is necessary to account for the existence of the large masses of gold which are sometimes found associated with quartz, at places where the reefs become narrow in pinched localities. The theory of precipitation cannot account for these. But that of earth-currents would naturally lead us to expect the phenomenon, because in such a locality, while the formation of quartz would be retarded, the formation of gold would be accelerated by the concentration of the current as already explained.

The hypothesis is thus well supported by prima facie evidence. For the experimental detection of earth-currents on goldfields I have strongly recommended the close observation of the most minute defections of the magnetic needle, especially in underground workings. I believe also that the use of the telephone, as in Prof. Trowbridge's experiments, will be of great service in indicating the lines of greatest conductivity in the earth's crust, and in enabling us to decide whether these are identical in goldfields with those lines in which the drifts contain the richest gold.

Angas Street, Adelaide, South Australia.

\section{THE PRIMITIVE TYPES OF MAMMALIAN MOLARS.}

SO much light has recently been thrown on the origin and mutual relations of the Mammalia by the labours of the Transatlantic palæontologists, that in the case of the limbs we have long since been able to trace the evolution of the specialized foot of the Horse from 
that of the five-toed Phenacodus (see NATURE, vol. xl. p. 57). Till quite lately, however, we have been unable to follow the mode of evolution of the more complicated forms of molar teeth from a common generalized type, although Prof. Cope, by his description of the so-called "tritubercular" type of molar structure, paved the way for the true history of this line of research.

The common occurrence of this tritubercular type of dentition among the mammals of the Lower Eocene at once suggests that we have to do with a very generalized form of tooth-structure ; and by a long series of observations Prof. H. F. Osborn, of Princeton, New Jersey, has succeeded, to a great extent, in showing how the more complicated modifications of molars may have been evolved from this generalized type. These observations are of so much importance towards a right understanding of the phylogenetic relationships of the Mammalia that a short summary cannot fail to be interesting to all students of this branch of zoology.
The tritubercular molar (Fig. A, 6), consists of three cusps, cones, or tubercles, arranged in a triangle, and so disposed that those of the upper jaw alternate with those of the lower. Thus, in the upper teeth (Fig. A, 7), there are two cusps on the outer side, and one cusp on the inner side of the crown; while in the lower teeth (Fig. A, $8,8 a$ ) we have one outer and two inner cusps. This type, when attained, appears to have formed a starting-point from which the greater number of the more specialized types have been evolved. The Monotremes, the Edentates, perhaps the Cetaceans, and the extinct group of Multituberculata (Plagiaulax and its allies), must, however, be excepted from the groups whose teeth have a tritubercular origin.

It appears probable, indeed, that "trituberculism," as this type of tooth-structure may be conveniently termed, was developed from a simple cone-like tooth during the Mesozoic period, and that in the Jurassic period it had developed into what is termed the primitive sectorial

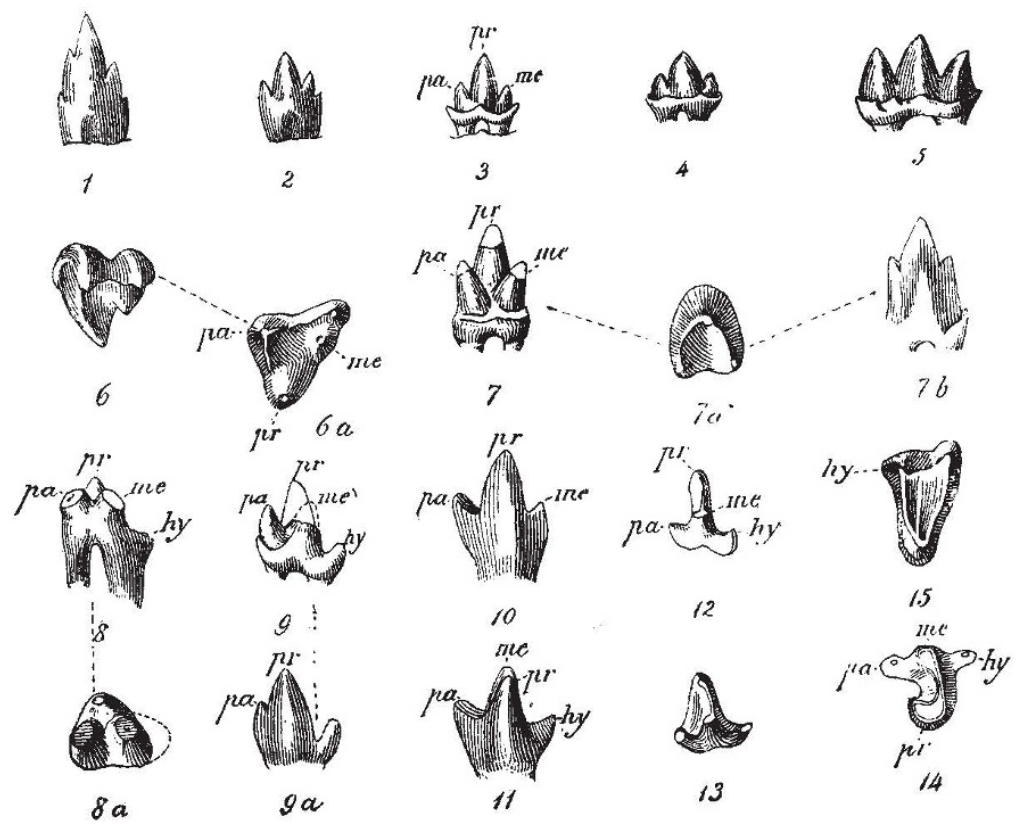

FIG. A.-Types of Molar Teeth of Mesozoic Mammals. 1-5, Triconodont Type (x, Dromatherium; 2, Microconoton; 3 , Amphilestes; 4 , Phascolotherium ; 5, Triconodon). 6, 7, 10, Tritubercular Type (6, Peralestes; 7 , Spalacotherium; ro, Asthenodon). 8-9, 11-15, Tuberculo-Sectorial Type (8, Amphitherium; 9, Peramus; Ir, Dryolestes; 12, 13, Amblotherium; 14, Achyrodon; $15, K u r t o d o n)$. 6 and 55 are upper, and the remainder lower molats. $p a$, paraconid; $p r$, protoconid; me, metaconid; $h y$, hypoconid. In the upper teeth the termination ends in cone.

type (Fig. A, 9). The stages of the development of "trituberculism" may, according to Prof. Osborn, be characterized as follows :-

(I) The Haplodont type.-This is a hypothetical type at present undiscovered, in which the crown of the tooth forms a simple cone, while the root is probably in most cases single, and not differentiated from the crown.

(a) The Protodont sub-type.-This sub-type is a slight advance on the preceding, and is represented by the American Triassic genus Dromatherium. The crown of the tooth (Fig. A, I) has one main cone, with fore-and-aft accessory cusps, and the root is grooved.

(2) The Triconodont type.-In this Jurassic type the crown (Fig. A, 4, 5) is elongated, with one central cone, and a smaller anterior and posterior cone situated in the same line; the root being differentiated into double fangs. Triconodon, of the English Purbeck, is the typical example.

(3) The Tritubercular type.-In this modification the crown is triangular (Fig. A, 7), and carries three main cusps or cones, of which the central one is placed in ternally in the upper teeth (Fig. A,6), and externally in the lower molars (Fig. A, 7). The teeth of the Jurassic Spalacotherium are typical examples. In the first and second types the molars are alike in both the upper and lower jaws; but in the third or tritubercular type, the pattern is the same in the teeth of both jaws, but with the arrangement of the homologous cusps reversed. These features are exhibited in Fig. B.

These three types are regarded as primitive, but in the following sub-types we have additional cusps grafted on to the primitive tritubercular triangle, as it is convenient to term the three original cusps.

(a) Tuberculo-sectorial sub-type.-This modification of the tritubercular type is found in the lower molars, like those of Didelphys. Typically the primitive tritubercular triangle is elevated, and the three cusps are connected by cross ridges, while a low posterior talon or heel is added (Fig. A, 9). This modification embraces a quinquetubercular form, in which the talon carries an inner and 
an outer cusp; while by the suppression of one of the primitive cusps we arrive at the quadritubercular tooth, bunodont tooth (Fig. C), like that of the Pigs. In the upper molars the primitive triangle in what is termed the secodont series may remain purely tricuspid. But by the development of intermediate tubercles in both the secodont and bunodont series a quinquetubercular form is reached; while the addition of a postero-internal cusp in the bunodont series gives us the sextubercular molar.

There is no doubt as to the homology of the three primary cusps in the upper and lower molars; and Prof. Osborn proposes the following series of terms for all the cusps above mentioned. The first secondary cusps (hypocone and hypoconid) respectively added to the upper and lower molars are also evidently homologous, and modify the crown from a triangular to a quadrangular form; but there is no homology between the additional secondary cusps of the upper molars termed protoconule and metaconule with the one termed ectoconid in the lower molars.
Terms applied to the cusps of molars:-

Upper Molars.

Antero-internal cusp

Postero. ,, ,, or 6th cusp $\quad=$ Protocone -pr.

- Paracone

Postero- ," ", $:$ = Metacone -me.

Anterior intermediate cusp $\quad . \quad=$ Protoconule $\mathrm{e}^{\mathrm{l}}-\mathrm{ml}$.

Posterior , , $\quad$ = Metaconule - pl.

Lower Molars.

Antero-external cusp

Postero- , ,

Antero-internal or "5th cusp

Intermediate, or antero-internal cusp

(in quadritubercular molars)

Postero-internal cusp

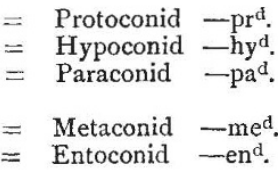

Having thus worked out the homology and relations of the tooth-cusps, Prof. Osborn gives some interesting observations on the principles governing the development
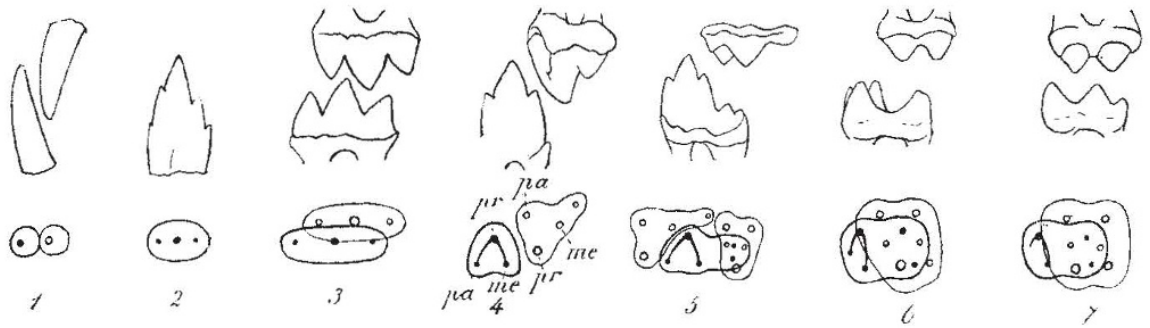
Fli. B.-Upper and Lower Molars in mutual apposition. I, Delphinus; 2, Dromatherinm; 3, Triconsdon; 4, Peralestes and Spalacotherium;
5, Didymictis; 6, Mioclentis: 7, Hyopsodus. Letters as in preceding figure.

of these cusps. It is considered that in the earliest Mammalian, or sub-mammalian, type of dentition (Haplodont), the simple cones of the upper and lower jaws

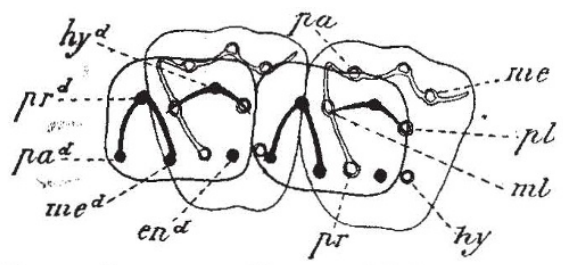

FrG. C.-Diagram of two upper and lower quadritubercular molars in apposition The cusps and ridges of the upper molars are in double lines, and those of the lower ones in black. The letters refer to the table given above. The lower molars are looked at from below, as if transparent.

interlocked with one another, as in the modern Dolphins (Fig. B, I). The first additions to the primitive protoconid

\section{OXFORD "PASS" GEOMETRY.}

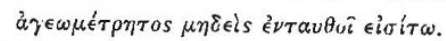

W HETHER poultry are to be regarded as descended from a primeval egg or a primeval hen, is a question on which some amount of scholastic ingenuity is supposed to have been exercised, and whether teachers or examiners are responsible for defective training in geometry is a question on which much might, more or less unprofitably, be said, and on which teachers and examiners may be expected to take different views. Happily for the mental equipment of the present generation of students, many teachers and examiners, avoiding barren controversy, have both laboured, as far as in them lies, to encourage soundness and thoroughness.

Probably, the old-world teachers who, hearing a "Euclid" lesson with the open Simson in their hand, looked upon "therefore" as an unwarrantable substitute for "wherefore," and could not be induced to accept appeared upon its anterior and posterior borders, and the growth of the para- and metaconids involved the necessity of the upper teeth biting on the outer side of the lower (Fig. B, 2), this condition being termed anisognathism, in contrast to the isognathism of the simple interlocking cones. In the typical tritubercular type (Fig. A, 7) it has been suggested that the para- and metaconids were rotated inwards from the anterior and posterior borders of the triconodont type; but it is quite possible that they may have been originally developed in their present position. By the alternation of the primitive triangle in the upper and lower jaws of the tritubercular type, the retention of an isognathous arrangement is permitted, the upper and lower teeth biting directly against one another.

Finally, Fig. C shows the mutual relations of the upper and lower teeth of the complicated quadritubercular molars, with the positions held by the primitive tritubercular triangles.

"angle $C A B$ " as a legitimate equivalent for what they saw in the text presented as "angle BAC," are fast disappearing, if not already extinct. Unfortunately, we are still under the influence of bad examination papers. Take, for instance, the papers set last year at Responsions. The sole directions from the examiner to the printer, necessary for getting these set up, might have been, and very likely were, as follows:-

\begin{tabular}{|c|c|c|c|c|c|}
\hline \multicolumn{2}{|c|}{ Trinity. } & \multicolumn{2}{|c|}{ Hilary. } & \multicolumn{2}{|c|}{ Michaelmas. } \\
\hline $\begin{array}{l}\text { (1) I. } 4 \\
\text { (2) I. } 14 \\
\text { (3) I. } 21 \\
\text { (4) I. } 22 \\
\text { (5) I. } 42\end{array}$ & $\begin{array}{l}\text { (6) I. } 46 \\
\text { (7) II. } 5 \\
\text { (8) II. } 7 \\
\text { (9) II. I2 } \\
\text { (I0) II. I4 }\end{array}$ & $\begin{array}{l}\text { (I) I. } 5 \\
\text { (2) I. Io } \\
\text { (3) I. } 17 \\
\text { (4) I. } 3 \text { I } \\
\text { (5) I. } 39\end{array}$ & $\begin{array}{l}\text { (6) I. } 48 \\
\text { (7) II. } 3 \\
\text { (8) II. } 6 \\
\text { (9) II. } 9 \\
\text { (I0) II. I } 4\end{array}$ & $\begin{array}{l}\text { (I) I. } 2 \\
\text { (2) I. } 7 \\
\text { (3) I. } 26 \\
\text { (4) I. } 34 \\
\text { (5) I. } 46\end{array}$ & $\begin{array}{l}\text { (6) I. } 45 \\
\text { (7) II. } 6 \\
\text { (8) II. 10 } \\
\text { (9) II. I2 } \\
\text { (I0) II. } 14\end{array}$ \\
\hline
\end{tabular}

r The symbols $m l$. and $p l$. should properly apply respectively to the metaconule and protoconule, but since they bear the opposite signification in Fig. C, they are placed as above. 